\title{
ANALYSIS OF CRYSTALLOGRAPHIC TEXTURE IN SMALL SAMPLE AREAS
}

\author{
K. HELMING ${ }^{1}$, B. RAUSCHENBACH ${ }^{2}$ and R. A. SCHWARZER ${ }^{3}$ \\ ${ }^{I}$ Technische Universität Dresden, Institut für Kristallographie und \\ Festkörperphysik, D-01062 Dresden, \\ ${ }^{2}$ Universität Augsburg, Institut für Physik, D-86135 Augsburg \\ ${ }^{3}$ Technische Universität Clausthal, Institut für Metallkunde und \\ Metallphysik, D-38678 Clausthal-Zellerfeld
}

(Received 20 February 1996)

\begin{abstract}
The description of texture by means of a small number of components (preferred orientations) is an exceptionally concise method. It may reveal relevant information about the texture modifying process even in those cases where the texture information, contained in the experimental pole figures, is rather limited. Some examples for texture estimates and interpretation of local textures in thin layers (SiC films synthesized by carbonization of silicon with fullerenes) and bulk materials (shear bands in brass and titanium) are presented.
\end{abstract}

KEY WORDS: Component fit method, shear band, deformation band, electron diffraction, titanium, brass, fullerenes

\section{IINTRODUCTION}

Solid state processes in polycrystalline materials are often associated with changes of crystallite orientation (Wassermann, 1939), and a microscopical understanding requires the determination of texture which is quantitatively given by the orientation distribution function (ODF). In the last two decades texture analysis has broadened significantly. Texture measurements are mostly intended to obtain directional diffraction data (pole figures). For cubic or hexagonal metals three to four (incomplete) pole figures are required to calculate the ODF. As a rule the angular resolution of $5^{\circ}$ is sufficient to describe typical textures of deformed or recrystallized metals and alloys. Much larger amounts of data (10 and more pole figures), however, are required to calculate the complete ODF for each crystalline phase (Helming, 1994) with multi-phase materials like ceramics, rocks or multilayers. ODF calculations proved to be more difficult for these materials because Bragg reflections often coincide, and the degree of overlapping increases with decreasing crystal symmetry.

In other cases only texture estimates can be obtained, because the quantity and quality of the measured pole figures is limited:

- Pole figures from very small sample regions $(\approx 1 \mu \mathrm{m})$ can be measured in selected area diffraction mode (SAD) with the transmission electron microscope (TEM) (Schwarzer, 1985). However, depending on the grain size, the statistics of the measured data may be poor, since only a small number of grains may fall in the measured field (Helming and Schwarzer, 1994; Helming et al., 1994). 
- X-ray measurements on thin layers $(10-100 \mathrm{~nm})$ usually provide low intensities, due to the small diffracting volumes. The statistics can be improved by using more intense x-rays from a synchrotron source (Geier et al., 1996).

In spite of these difficulties, which are caused by the conditions of measurement, local textures may still be interpreted by using the component model. In this paper two examples for estimates of local texture are presented. The first is concerned with local textures in deformation/shear bands in metals starting from rather incomplete pole figures measured with the TEM. In the second example the texture formation during SiC synthesis by carbonization of (100) silicon with fullereness was studied using synchrotron radiation.

\section{TEXTURE APPROXIMATION}

Depending on the method used to represent texture, the amount of required ODF data may be extremely high. Furthermore large numbers of samples have to be compared with each other in order to find out some relevant texture information about the process modifying texture. In these cases methods of texture approximation (or data reduction) working with model functions like spherical harmonics or Gaussian distributions are indispensable. Most widely used is the series expansion method with generalized spherical harmonics (Bunge, 1965):

$$
f(g)=\sum_{1} \sum_{m, n} C_{1}^{m m} T_{1}^{m m}(g) .
$$

They form an orthogonal system of basic functions and are periodic in the whole $G$ space (period length $2 \pi / 1$ ). In addition to numerical advantages, mean values of anisotropic properties can be calculated efficiently by means of the corresponding $\mathrm{C}$ coefficients.

Orientations $g$ are usually described by $g=[\omega, n]$ with the rotation axis $n$ and the rotation angle $\omega$, or by Euler angles $g=\left(\varphi, \Phi, \varphi_{2}\right)$, respectively. The relationship between both representations reads

$$
\cos \frac{\omega}{2}=\cos \left(\frac{\varphi_{1}+\varphi_{2}}{2}\right) \cos \left(\frac{\Phi}{2}\right) ; \mathbf{n} \sin \frac{\omega}{2}=\left(\begin{array}{c}
\sin \left(\frac{\varphi_{1}-\varphi_{2}}{2}\right) \sin \left(\frac{\Phi}{2}\right) \\
-\cos \left(\frac{\varphi_{1}-\varphi_{2}}{2}\right) \sin \left(\frac{\Phi}{2}\right) \\
\sin \left(\frac{\varphi_{1}+\varphi_{2}}{2}\right) \cos \left(\frac{\Phi}{2}\right)
\end{array}\right)
$$

For a sharp texture a large number of $\mathrm{C}$ coefficients is necessary, whilst rather a small number of preferred orientations may be sufficient to describe its main features. In such cases the ODF approximation by means of texture components

$$
f(g)=F+\sum_{c} I^{c} f^{c}(g) \text { with } F+\sum_{c} I^{c}=1 \text { and } \oint_{G} f^{c}(g) d g=1 \text {, }
$$


is superior (Wassermann, 1939; Bunge, 1982; Lücke et al., 1986; Matthies et al., 1987-1990). A component $\mathrm{c}$ is described by a model function $\mathrm{f}^{\mathrm{c}}(\mathrm{g})$, which is locally limited in $G$ space, and an intensity $I^{c}$ which describes the volume fraction of all crystallites of this component. The quantity $\mathrm{F}$ gives the volume fraction of the crystallites which are randomly oriented in the sample. The model function (Matthies et al., 1987-1990)

$$
\mathrm{f}^{\mathrm{c}}(\mathrm{g})=\mathrm{f}^{\mathrm{c}}\left(\mathrm{g}, \mathrm{g}^{\mathrm{c}}, \mathrm{S}^{\mathrm{c}}\right)=\mathrm{N}^{\mathrm{c}} \mathrm{e}^{\mathrm{s}^{\mathrm{c}} \cos \Phi^{\mathrm{c}}} \quad \text { with } \mathrm{S}^{\mathrm{c}}=\frac{\ln 2}{1-\cos \left(\mathrm{b}^{\mathrm{c}} / 2\right)}
$$

has a maximum at a preferred orientation $\mathrm{g}^{\mathrm{c}}$, and decreases with increasing orientation distance $\widetilde{\omega}^{c}$. It is defined by the rotation angle of the orientation difference $\tilde{\mathbf{g}}^{\mathrm{c}}=\left[\tilde{\omega}, \tilde{\mathbf{n}}^{\mathrm{c}}\right]=\mathrm{g}^{\mathrm{c}} \mathrm{g}^{-1}$ between $\mathrm{g}^{\mathrm{c}}=\left[\omega^{\mathrm{c}}, \mathbf{n}^{\mathrm{c}}\right]$ and $\mathrm{g}=[\omega, \mathbf{n}]$ :

$$
\begin{aligned}
\cos \frac{\widetilde{\omega}^{c}}{2} & =\cos \frac{\omega^{c}}{2} \cos \frac{\omega}{2}+n^{c} \cdot n \sin \frac{\omega^{c}}{2} \sin \frac{\omega}{2} \\
& =\cos \frac{\varphi_{1}^{c}-\varphi_{1}}{2} \cos \frac{\varphi_{2}^{c}-\varphi_{2}}{2} \cos \frac{\Phi^{c}-\Phi}{2}-\sin \frac{\varphi_{1}^{c}-\varphi_{1}}{2} \sin \frac{\varphi_{2}^{c}-\varphi_{2}}{2} \cos \frac{\Phi^{c}+\Phi}{2}
\end{aligned}
$$

If the decrease in intensity does not depend on the rotation axis, $\tilde{\mathbf{n}}^{\mathrm{c}}$,

$$
\tilde{\mathbf{n}}^{\mathrm{c}} \sin \frac{\tilde{\omega}^{\mathrm{c}}}{2}=-\mathbf{n} \sin \frac{\omega}{2} \cos \frac{\omega^{\mathrm{c}}}{2}+\mathbf{n}^{\mathrm{c}} \sin \frac{\omega^{\mathrm{c}}}{2} \cos \frac{\omega}{2}+\mathbf{n} \times \mathbf{n}^{\mathrm{c}} \sin \frac{\omega^{\mathrm{c}}}{2} \sin \frac{\omega}{2},
$$

the component is called isotropic (Figure 1). The value $b^{c}$ characterizes the spread of the preferred orientation and is called halfwidth of the component.

Pole figures which are measured in a diffraction experiment can be understood as two-dimensional projections of the three-dimensional ODF:

$$
\tilde{P}_{h}(y)=\frac{1}{2}\left[P_{h}(y)+P_{-h}(y)\right]=\frac{1}{2} \int_{0}^{\pi}[f([\varphi,+y \| h])+f([\varphi,-y \| h])] d \varphi .
$$

Here $\mathrm{g}_{\varphi}=[\varphi, \mathbf{h} \| \mathbf{y}]$ with $0 \leq \varphi \leq \pi$ describes all orientations with their lattice plane normal $\mathbf{h}$ lying parallel (or antiparallel) with the scattering vector $\mathbf{y}$. The direction $\mathbf{y}$ is named sample direction, since it is related to the sample coordinate system. As a consequence of Friedel's law, pole figures are affected by an additional inversion center allowing only reduced pole figures, $\tilde{\mathbf{P}}_{\mathbf{h}}(\mathbf{y})$, to be measured. The pole figures measured in the diffraction experiment read

$$
\tilde{D}_{\mathbf{h}_{\mathrm{i}}}\left(\mathbf{y}_{\mathrm{r}}\right)=\mathbf{N}_{\mathbf{h}_{\mathbf{i}}} \tilde{\mathbf{P}}_{\mathbf{h}_{\mathrm{i}}}\left(\mathbf{y}_{\mathrm{r}}\right)
$$

where $r$ marks the sample directions and $i$ the Miller indices $i \equiv(h k l)$ of the measured pole figures, $\tilde{D}_{h_{i}}(y)$. The factors $N_{h}$ depend on structure, phase fractions and absorption in a complex manner (Bunge et al., 1989). In the general case they must be treated as unknown parameters.

Now a component description of the ODF, $\mathrm{f}(\mathrm{g})$, is searched, trying to find the best fit of the experimental data $\tilde{D}_{h_{i}}(y)$ with the pole figures $D_{h_{i}}^{M}\left(y_{r}\right)$ which have been 


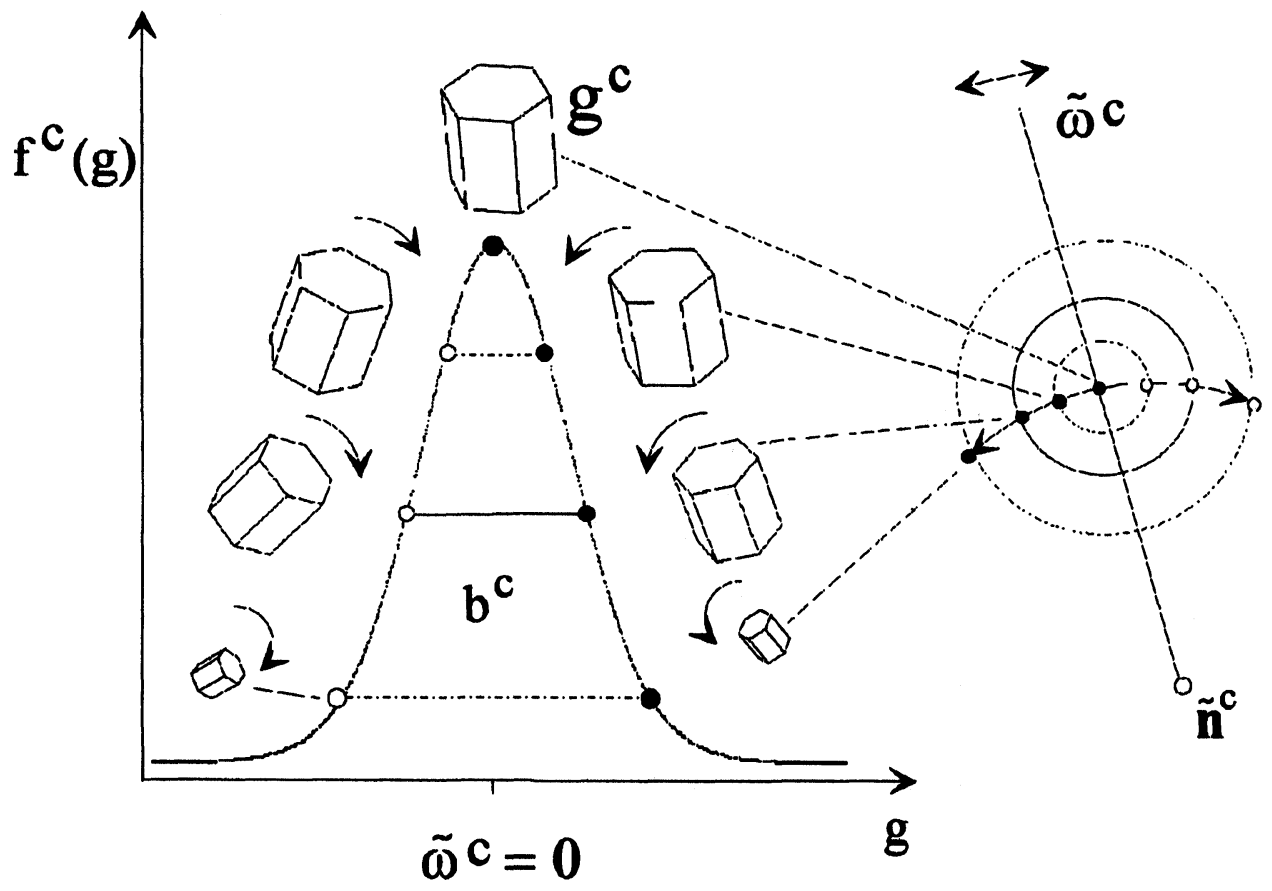

Figure 1 A Gaussian model function of a component with a maximum at a preferred orientation $\mathrm{g}^{\mathrm{c}} . \mathrm{f}^{\mathrm{c}}(\mathrm{g})$ decreases with increasing orientation distance $\tilde{\omega}^{c}$. If the decrease in intensity does not depend on the rotation axis $\tilde{\mathbf{n}}^{\mathrm{c}}$, the component is called isotropic.

recalculated using the component model for all measured sample directions $\mathrm{y}_{\mathrm{r}}$. The component parameters $I^{c}, g^{c}$ and $b^{c}$ and the values $N_{h_{i}}$ can be determined by solving the least squares problem ( $\mathrm{w}_{\mathrm{ir}}$ are weight factors)

$$
\sum_{i, r} w_{i r}\left[\tilde{D}_{h_{i}}\left(y_{r}\right) / N_{h_{i}}-\sum I^{c} \tilde{P}_{h_{i}}^{M}\left(g^{c}, b^{c}, y_{r}\right)\right]^{2} \Rightarrow \text { Min. }
$$

In order to determine the parameters $g^{c}$ and $b^{c}$ by a non-linear algorithm, first estimates are necessary which may be obtained interactively from the graphical representation of the difference pole figures

$$
\Delta \tilde{D}_{h_{i}}\left(y_{r}\right)=\frac{\tilde{D}_{h_{i}}\left(y_{r}\right)-\tilde{D}_{h_{i}}^{M}\left(y_{r}\right)}{N_{h_{i}}} .
$$

This procedure is explained in more detail in (Helming, 1994; Helming and Eschner, 1990). The calculation of the model pole figures $\tilde{\mathrm{P}}_{\mathrm{h}_{\mathrm{i}}}^{M}$ follows from eqs. (5), (7) and (8). 
The component description enables an efficient concentration of texture information. An estimate of the ODF is obtained which takes into account only the smallest necessary number of components. Estimates may be appropriate if the quality or quantity of measured data does not allow a precise calculation. For thin layers the number I of experimental pole figures and the range $Y_{i}$ (with $y_{r} \in Y_{i}$ ) of measured sample directions are limited, because of the poor statistics perpendicular to the layer normal. The approach to determine texture components requires that the number of available pole figures and the measured ranges are large enough such that any crystal orientation can be determined unambiguously. The least necessary amount of texture information in experimental pole figures only depends on crystal symmetry and the type of Miller indices of the diffracting lattice planes. The determination of minimal pole figure ranges (MPR) containing a minimum amount of texture information is explained in (Helming, 1992).

\section{Example 1: Shear Bands in Brass and Titanium}

The high sensitivity of electron diffraction favours the analysis of texture in fine grain materials from very small regions. The experimental selected area diffraction (= SAD) pole figures are incomplete with blind ranges forming a spherical biangle (length $180^{\circ}$, width $<80^{\circ}$ ) on the pole sphere. Correction procedures have been developed to interpret quantitatively the diffracted intensities (Schwarzer, 1983). Allowance is made for the increase in diffracting volume and absorption with increasing sample tilt. To improve the statistics several pole figures may be measured along the area of interest (e.g. shear band) and are then added up before the texture estimate is carried out.

Figure 2 shows the 111,200 and 220 SAD pole figures of a shear band in brass. The minimum width of a biangle on the pole sphere can be calculated using the MPR program (Helming, 1992). For the reflections under consideration and for cubic crystal symmetry this angle is $90^{\circ}$. Since the width of the measured biangle in this example was $104^{\circ}$ (length $180^{\circ}$ ), every preferred orientation can be determined unambiguously. The texture was estimated using both the series expansion method (positivity method, (Dahms and Bunge, 1989)) and the component model. The recalculated pole figures are shown in Figure 2. Both methods yield equivalent results, if the measured ranges are large enough.

Figure 3 shows pole figures for a deformation band and a shear band in titanium. With hexagonal materials only 10.0 and 10.2 pole figures can be measured in SAD mode of the TEM. The other reflections are not sufficiently separated and overlap, due to the limited dispersion of electron diffraction. For these two pole figures the MPR width of the biangle is $112^{\circ}$. Unfortunately the experimentally accessible range on the pole sphere was further limited to only $102^{\circ}$, since part of the specimen was shaded by the sample holder at large angles of tilt. As a consequence not every preferred orientation can be described unambiguously, and a rough texture estimate was carried out by considering only those components which have at least two poles falling into the measured ranges on the pole sphere. Recalculated pole figures (including the 00.1 pole figure which cannot be measured) are displayed side by side along with the experimental pole figures for a visual comparison. The theoretical 00.1 pole figures fit amazingly well with the experimentally ones. They show a splitted maximum parallel to the shear normal, SN. The 10.0 pole figures, however, still differ from each other, particularly for the shear band. Strong components with $h_{i}=\{10.0\}$ parallel to the direction of shear, SD, are found only in the deformation band which might be an indication of different mechanisms of the formation of deformation and shear bands. 
(111)
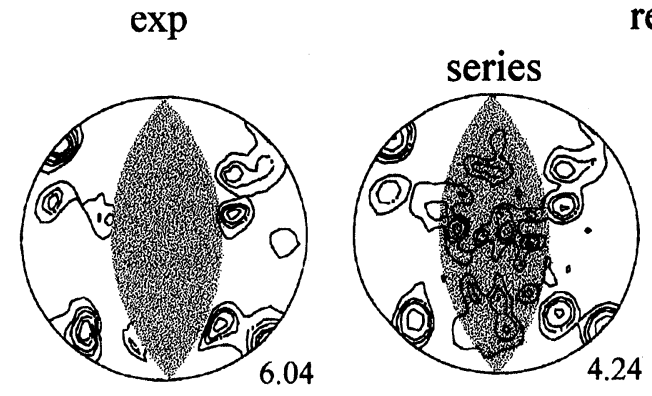

rec
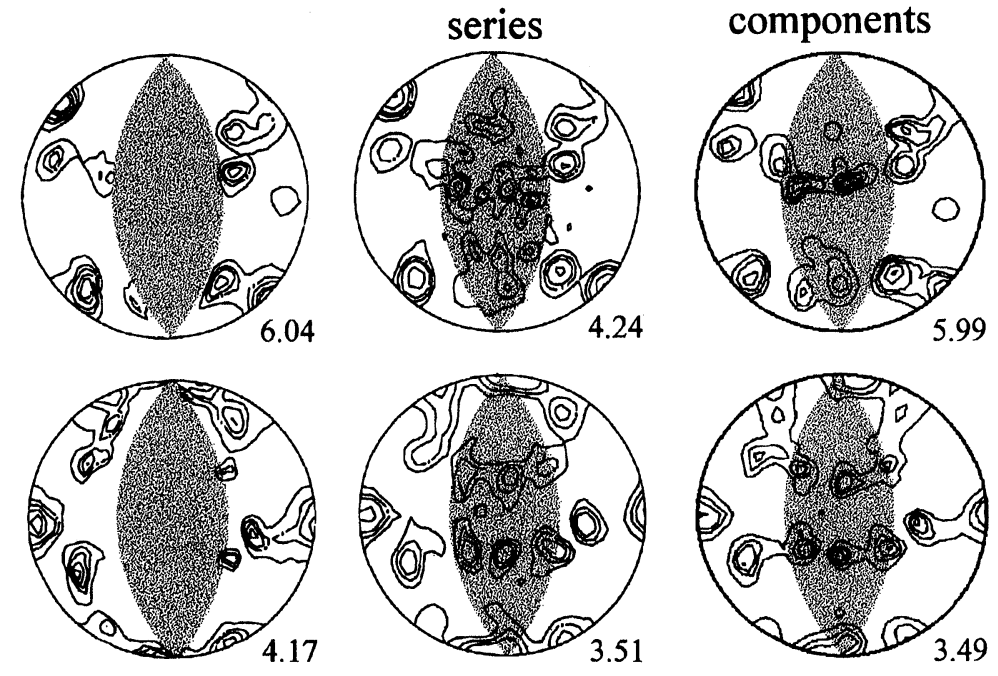

(100)
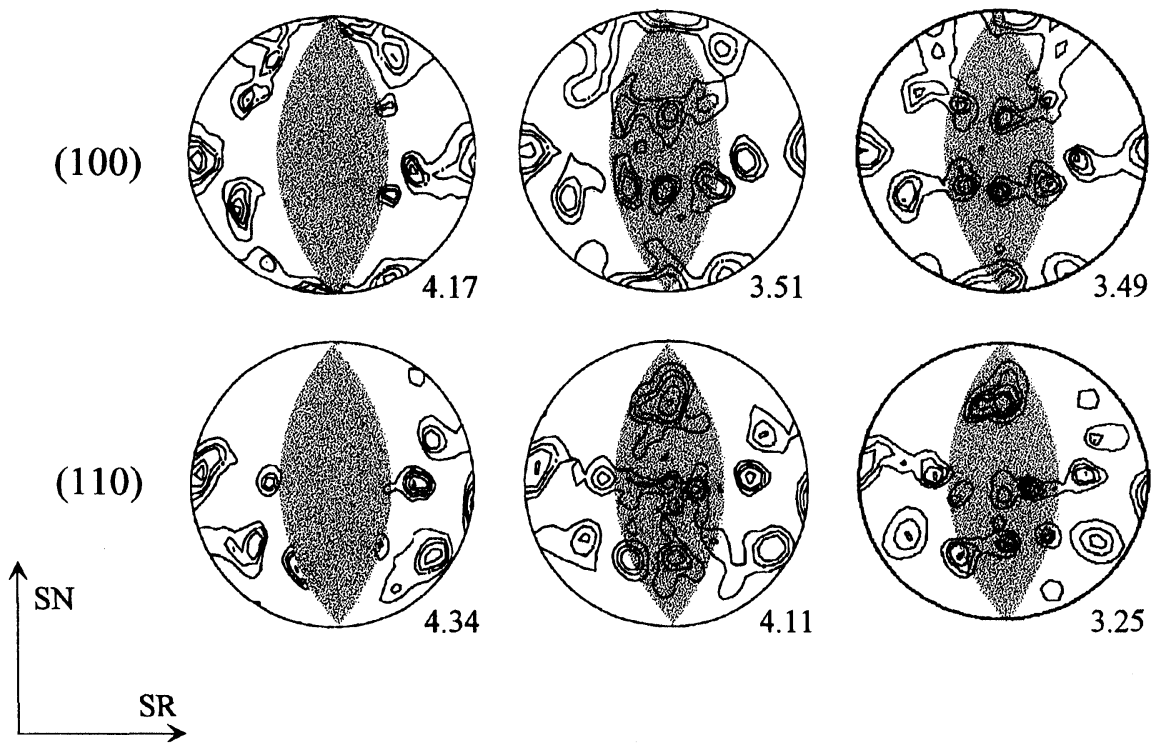

Figure 2 Incomplete pole figures of a shear band in brass in comparison with the complete pole figures recalculated with the series expansion method and the component method. Unmeasured ranges are shaded. The maximum intensity levels are given on the right bottom corners. SN stands for the shear band normal, SR for the direction of shear, and QR for the transverse direction.

\section{Example 2: Texture of SiC Layers Prepared by $C_{60}$ Carbonization of $\mathrm{Si}$}

In this work very thin $\mathrm{SiC}$ layers have been prepared by $\mathrm{C}_{60}$ carbonization at low temperatures. At the surface of $\mathrm{Si}$ the fragmentation of the $\mathrm{C}_{60}$ molecules leads to highly reactive carbon atoms. The $\mathrm{SiC}$ layers were characterized by synchrotron radiation diffraction in order to study quantitatively the crystallographic orientations of the $\mathrm{SiC}$ layers in dependence on substrate temperature and on layer thickness. $\mathrm{C}_{60}$ microcrystalline powders had been synthesized with a purity of $99.9 \%$ and were used for thermal evaporation onto $\mathrm{Si}(001)$ substrates under high vacuum. The deposition rate was kept constant at $0.01 \mathrm{~nm} / \mathrm{s}$. The substrate temperature ranged from $700^{\circ} \mathrm{C}$ to 900 ${ }^{\circ} \mathrm{C}$, and the film thickness from $50 \mathrm{~nm}$ to $300 \mathrm{~nm}$ (for details see (Henke et al., 1995)). The samples were investigated at the German Synchrotron Radiation Source DESY. 
DB

exp.

rec.
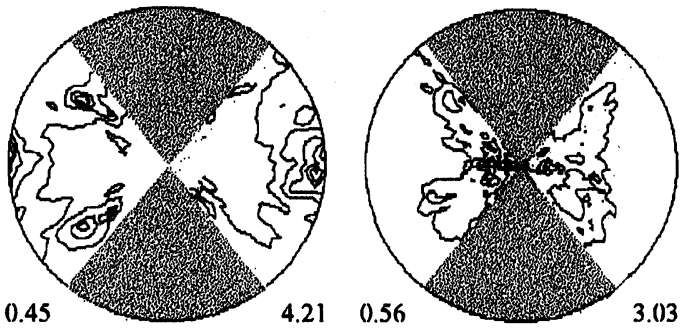

(001)
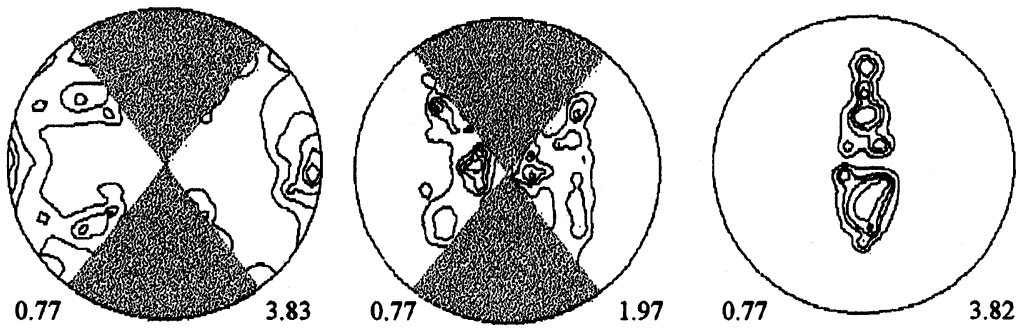

SB

exp.
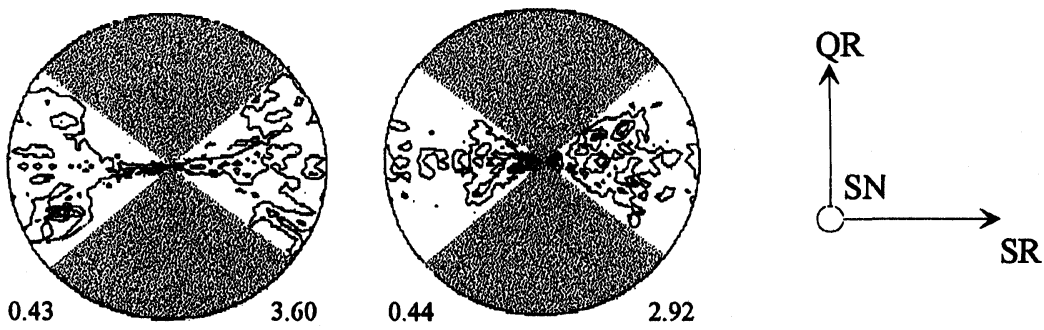

rec.
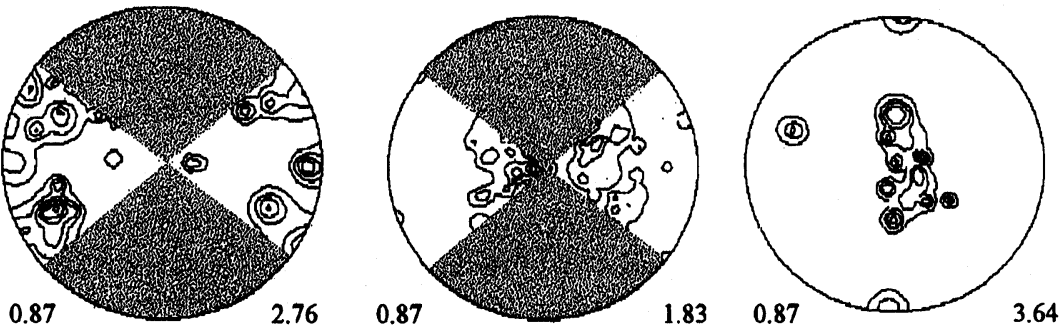

Figure 3 Incomplete pole figures of a shear band, SB, and a deformation band, SB, in titanium in comparison with the complete pole figures, recalculated with the component method. Unmeasured ranges are shaded. The minimum and maximum intensity levels are given on the left and right bottom corners, respectively. 

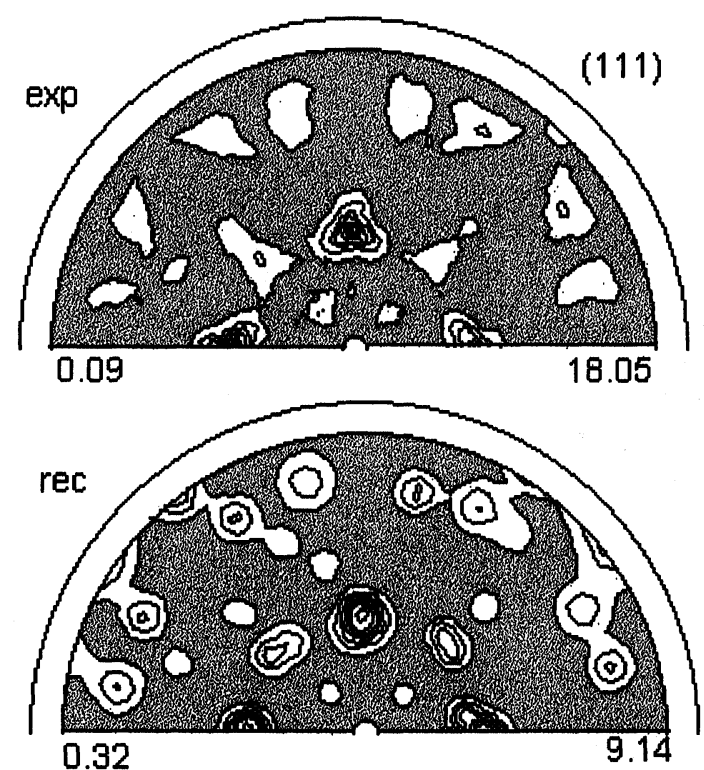

Figure 4 The experimentally determined and recalculated 111 pole figure of $170 \mathrm{~nm} \mathrm{SiC} \mathrm{film} \mathrm{on}$ $\mathrm{Si}(001)$ prepared at $800^{\circ} \mathrm{C}$ (cf. Table 1 ). The measured ranges with $\tilde{\mathbf{P}}_{\mathrm{h}}(\mathbf{y})<1$ are shaded. The minimum and maximum intensity levels are given on the left and right bottom corners, respectively.

A diffractometer with an Eulerian cradle allowed the measurement of pole figures. The experiments were carried out with a silicon double crystal monochromator in the primary beam. The pole figures were measured at step widths of $1^{\circ}$ in both the azimuthal $(\varphi)$ and the polar $(\vartheta)$ direction (for details see (Helming et al., 1995)).

The investigation of textures of thin films formed in the stage of nucleation (before the growth process has started) requires intense synchrotron radiation and very long measuring times. Due to the cubic substrate with (001) orientation, the sample symmetry of $\mathrm{SiC}$ may contain a four-fold axis parallel to the surface normal. Only incomplete 111 pole figures were measured for sample directions $\mathbf{y}=(\vartheta, \varphi)$ with $0^{\circ} \leq \varphi \leq 180^{\circ}$ and $4^{\circ} \leq \vartheta \leq 84^{\circ}$. Since from MPR calculation follows $26^{\circ} \leq \vartheta_{\mathrm{MPR}} \leq 84^{\circ}$, the determination of preferred orientations is unambiguously possible in each case.

By visual comparison of the measured 111 pole figures (Figure 4, 5a-d), a common texture type can be recognized which is most pronounced for the sample with the largest thickness $(170 \mathrm{~nm})$. Its texture shows a tetragonal sample symmetry which can be described by nine components (Table 1$)$. The strongest components $(c=2,3)$ are rotated against the cube component $(c=1)$ by a rotation about the $(100)$ axis by $45^{\circ}$ (socalled Goss component in metal research). Other correlations between components may be calculated using eqs. (5), (6) and the relation $\left(\varphi_{1}, \Phi, \varphi_{2}\right)=\left(\varphi_{1}, \Phi, \varphi_{2}+90^{\circ}\right)$ that follows from cubic crystal symmetry.

The textures of the remaining samples (Figure 5) were calculated by a non-linear approximation using the sample with the thickness of $170 \mathrm{~nm}$ as starting estimate. Their component description is given in Table 2a-d. Components 5 and 6 of the samples prepared at temperatures $\leq 750^{\circ} \mathrm{C}$ (Figures $5 \mathrm{~b}-\mathrm{d}$ ) are the most intense ones. In 

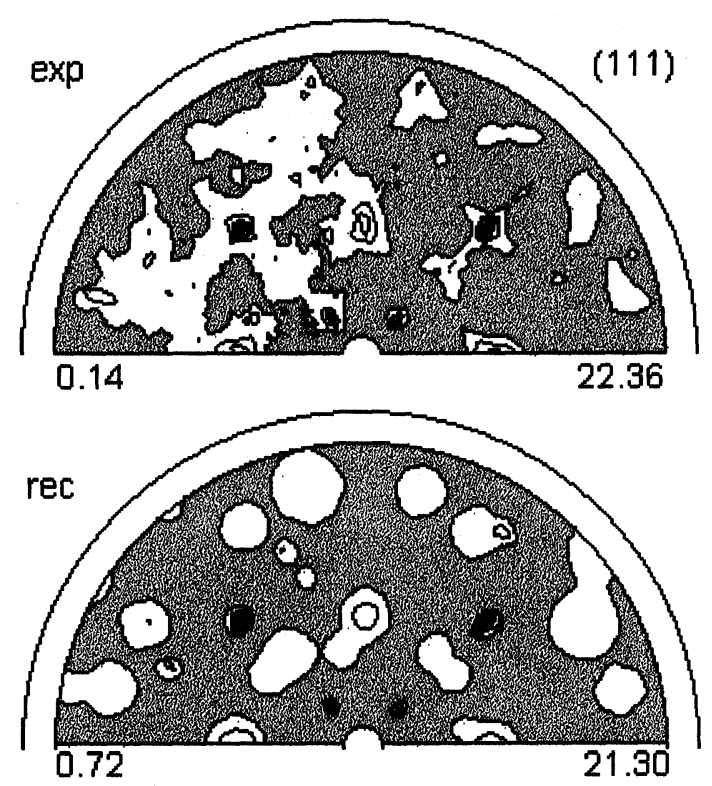

Figure 5 Experimentally determined and recalculated 111 pole figures of $\mathrm{SiC}$ film on $\mathrm{Si}(001)$. The measured ranges with $\tilde{\mathbf{P}}_{\mathrm{h}}(\mathbf{y})<1$ are shaded. The minimum and maximum intensity levels are given on the left and right bottom corners, respectively. SiC films were prepared with a thickness of a) $100 \mathrm{~nm}$ at $900^{\circ} \mathrm{C}$.
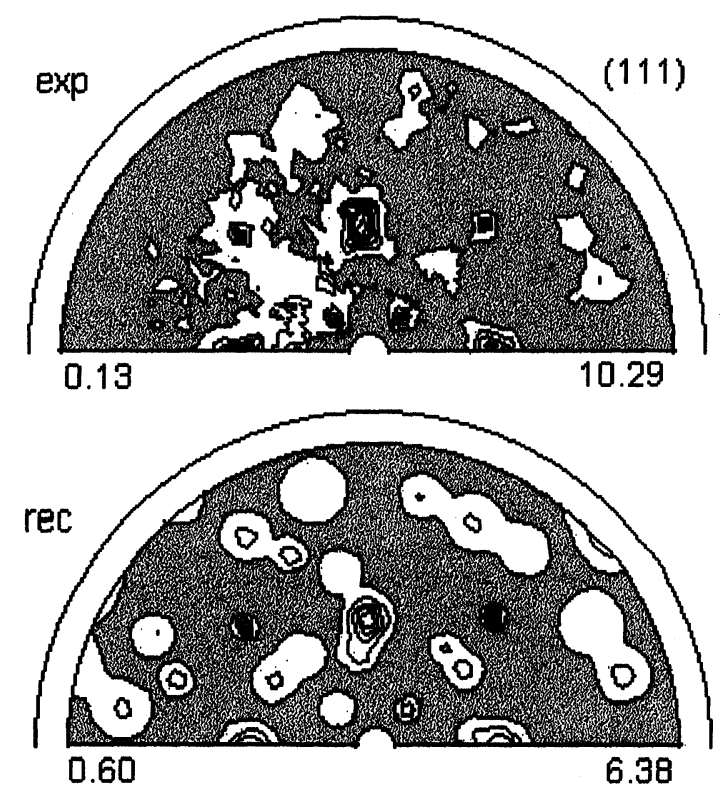

Figure 5 Experimentally determined and recalculated 111 pole figures of $\mathrm{SiC}$ film on $\mathrm{Si}(001)$. The measured ranges with $\widetilde{\mathbf{P}}_{\mathrm{h}}(\mathbf{y})<1$ are shaded. The minimum and maximum intensity levels are given on the left and right bottom corners, respectively. SiC films were prepared with a thickness of b) $50 \mathrm{~nm}$ at $700^{\circ} \mathrm{C}$. 

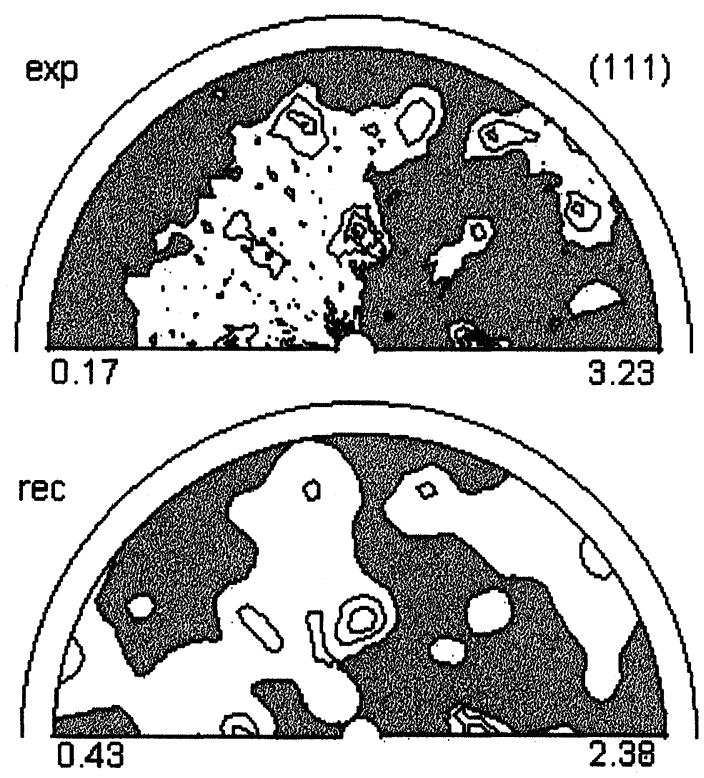

Figure 5 Experimentally determined and recalculated 111 pole figures of $\mathrm{SiC}$ film on $\mathrm{Si}(001)$. The measured ranges with $\tilde{\mathbf{P}}_{\mathrm{h}}(\mathbf{y})<1$ are shaded. The minimum and maximum intensity levels are given on the left and right bottom corners, respectively. SiC films were prepared with a thickness of c) $70 \mathrm{~nm}$ at $750^{\circ} \mathrm{C}$.

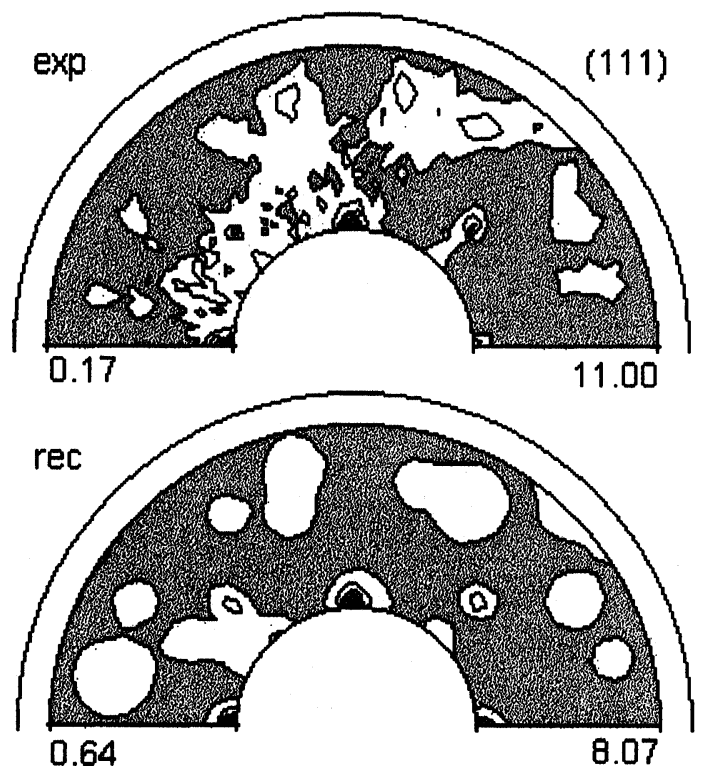

Figure 5 Experimentally determined and recalculated 111 pole figures of $\mathrm{SiC}$ film on $\mathrm{Si}(001)$. The measured ranges with $\tilde{\mathbf{P}}_{\mathbf{h}}(\mathbf{y})<1$ are shaded. The minimum and maximum intensity levels are given on the left and right bottom corners, respectively. SiC films were prepared with a thickness of d) $300 \mathrm{~nm}$ at $750^{\circ} \mathrm{C}$. 
Figure 5a (substrate temperature $\mathrm{T}=900^{\circ} \mathrm{C}$ ) the cube component is significant, in addition to component 6 . In most cases the changes of the component parameters are small. E.g. the orientation distance between the components $c=1$ of the samples prepared at temperatures $\geq 800^{\circ} \mathrm{C}$ (Figures 4 and $5 \mathrm{a}$ ) is given by $\tilde{\omega}=2.1^{\circ} \mathrm{C}$. This follows with $\mathrm{g}_{4 \mathrm{a}}^{1}=\left(82.2^{\circ}, 2.3^{\circ}, 9.3^{\circ}+90^{\circ}\right)$ and $\mathrm{g}_{5_{\mathrm{a}}}^{1}=\left(130.6^{\circ}, 17^{\circ}, 48.9^{\circ}\right)$ from eq. (5).

\section{SUMMARY}

The experimental SAD pole figures from shear bands and deformation bands in brass agree well with theoretical pole figures recalculated with the series expansion method and the component method. For hexagonal materials, however, only two rather incomplete SAD pole figures can be measured in the TEM. This number is not sufficient for ODF calculation using the series expansion method, whilst a semi-quantitative texture analysis is still possible using the component model. A good fit of the recalculated pole figures to experimental SAD pole figures has been obtained, and immeasurable pole figures, particularly the 00.1 pole figure, can be obtained. The estimates required no more than 19 components by which the high efficiency of this method is demonstrated.

The experimental results give a first insight in the dependence of the growth of thin $\mathrm{SiC}$ layers on $\mathrm{Si}(001)$ on the temperature and layer thickness. With increasing temperature and substrate thickness of the $\mathrm{SiC}$ film the misorientation decreases.

Main benefits of the texture component model are:

- As a rule the use of components reduces the number of necessary data for quantitative texture description. Processes and properties correlated with texture are understood more readily due to the high compression of texture information.

- Texture estimates can be obtained from incomplete pole figures with uncommon measured ranges, independent of crystal symmetry.

Table 1 Table of components for the two-phase system $\mathrm{SiC}$ on $\mathrm{Si}(001)$.

\begin{tabular}{|c|c|c|c|c|c|}
\hline \multicolumn{2}{|c|}{$\begin{array}{c}T=800^{\circ} \mathrm{C} \\
d=170 \mathrm{~nm}\end{array}$} & \multicolumn{4}{|c|}{ Isotropic part: $31.88 \%$} \\
\hline$C$ & $I[\%]$ & $\left.\varphi_{I} I^{\circ}\right]$ & $\Phi\left[{ }^{\circ}\right]$ & $\left.\varphi_{2} l^{\circ}\right]$ & $b\left[^{\circ}\right]$ \\
\hline 1 & 2.3 & 82.2 & 2.3 & 9.3 & 9.0 \\
\hline 2 & 10.0 & 0.9 & 40.7 & 3.1 & 7.5 \\
\hline 3 & 14.7 & 90.9 & 41.6 & 1.6 & 10.8 \\
\hline 4 & 6.9 & 25.9 & 24.1 & 89.0 & 7.1 \\
\hline 5 & 8.3 & 117.4 & 25.1 & 89.1 & 8.2 \\
\hline 6 & 9.7 & 159.1 & 25.8 & 86.5 & 9.6 \\
\hline 7 & 7.5 & 69.2 & 25.3 & 88.6 & 7.4 \\
\hline 8 & 4.2 & 138.0 & 36.9 & 43.2 & 9.6 \\
\hline 9 & 4.6 & 88.1 & 41.0 & 29.2 & 10.0 \\
\hline
\end{tabular}


Table 2 Tables of components for the two-phase system $\mathrm{SiC}$ on $\mathrm{Si}(001)$. SiC films were prepared with a thickness of a) $100 \mathrm{~nm}$ at $900^{\circ} \mathrm{C}$, b) $50 \mathrm{~nm}$ at $700^{\circ} \mathrm{C}$, c) $70 \mathrm{~nm}$ at $750^{\circ} \mathrm{C}$, and d) $300 \mathrm{~nm}$ at $750^{\circ} \mathrm{C}$.

a)

\begin{tabular}{|c|c|c|c|c|c|}
\hline \multicolumn{2}{|c|}{$\begin{array}{c}T=900^{\circ} \mathrm{C} \\
d=100 \mathrm{~nm}\end{array}$} & \multicolumn{4}{|c|}{ Isotropic part: $71.56 \%$} \\
\hline$C$ & $I[\%]$ & $\left.\varphi_{1} l^{\circ}\right]$ & $\Phi\left[{ }^{\circ}\right]$ & $\left.\varphi_{2} l^{\circ}\right]$ & $b\left[^{\circ}\right]$ \\
\hline 1 & 4.1 & 130.6 & 1.7 & 48.9 & 1.9 \\
\hline 2 & 1.3 & 1.3 & 40.9 & 2.6 & 4.3 \\
\hline 3 & 2.9 & 89.6 & 40.3 & 6.4 & 8.7 \\
\hline 4 & 3.6 & 19.1 & 24.9 & 6.0 & 6.5 \\
\hline 5 & 3.7 & 108.7 & 23.8 & 7.1 & 7.9 \\
\hline 6 & 6.9 & 158.7 & 25.9 & 85.6 & 9.6 \\
\hline 7 & 3.1 & 70.6 & 25.5 & 83.2 & 6.7 \\
\hline 8 & 1.4 & 134.9 & 37.8 & 44.9 & 2.3 \\
\hline 9 & 1.5 & 91.6 & 43.6 & 29.4 & 1.9 \\
\hline
\end{tabular}

b)

\begin{tabular}{|c|c|c|c|c|c|}
\hline \multicolumn{2}{|c|}{$\begin{array}{l}T=700^{\circ} \mathrm{C} \\
d=50 \mathrm{~nm}\end{array}$} & \multicolumn{4}{|c|}{ Isotropic part: $59.69 \%$} \\
\hline$C$ & I[\%] & $\varphi_{1}\left[^{\circ}\right]$ & $\Phi\left[^{\circ}\right]$ & $\left.\varphi_{2} l^{\circ}\right]$ & $b\left[^{\circ}\right]$ \\
\hline 1 & 1.4 & 53.6 & 0.7 & 38.9 & 3.0 \\
\hline 2 & 3.2 & 0.3 & 42.1 & 3.9 & 7.8 \\
\hline 3 & 6.5 & 92.0 & 42.7 & 5.8 & 8.2 \\
\hline 4 & 3.3 & 23.3 & 24.1 & 3.9 & 7.1 \\
\hline 5 & 6.1 & 115.8 & 23.6 & 3.9 & 9.3 \\
\hline 6 & 7.0 & 161.4 & 25.2 & 84.1 & 11.3 \\
\hline 7 & 5.0 & 73.2 & 24.5 & 84.3 & 7.9 \\
\hline 8 & 2.8 & 138.1 & 38.4 & 44.8 & 5.3 \\
\hline 9 & 4.8 & 86.1 & 40.4 & 31.2 & 8.9 \\
\hline
\end{tabular}

c)

\begin{tabular}{|c|c|c|c|c|c|}
\hline \multicolumn{2}{|c|}{$\begin{array}{l}T=750^{\circ} \mathrm{C} \\
d=70 \mathrm{~nm}\end{array}$} & \multicolumn{4}{|c|}{ Isotropic part: $41.66 \%$} \\
\hline$C$ & I[\%] & $\varphi_{1}\left[^{\circ}\right]$ & $\Phi\left[{ }^{\circ}\right]$ & $\left.\varphi_{2} L^{\circ}\right]$ & $b\left[^{\circ}\right]$ \\
\hline 1 & 2.9 & 65.5 & 3.8 & 23.2 & 11.1 \\
\hline 2 & 0.9 & 5.4 & 41.8 & 3.2 & 4.8 \\
\hline 3 & 2.8 & 89.2 & 40.3 & 3.9 & 9.2 \\
\hline 4 & 1.6 & 19.1 & 25.6 & 3.3 & 7.6 \\
\hline 5 & 10.4 & 150.0 & 14.7 & 63.6 & 18.6 \\
\hline 6 & 14.1 & 151.6 & 28.1 & 3.5 & 17.9 \\
\hline 7 & 3.0 & 62.8 & 24.7 & 3.0 & 10.4 \\
\hline 8 & 3.2 & 139.7 & 29.1 & 44.0 & 15.4 \\
\hline 9 & 19.4 & 88.1 & 43.9 & 30.0 & 22.1 \\
\hline
\end{tabular}


Table 2 (cont'd)

d)

\begin{tabular}{|c|c|c|c|c|c|}
\hline \multicolumn{2}{|c|}{$\begin{array}{c}T=750^{\circ} \mathrm{C} \\
d=300 \mathrm{~nm}\end{array}$} & \multicolumn{4}{|c|}{ Isotropic part: $63.56 \%$} \\
\hline$C$ & I[\%] & $\varphi_{I}\left[^{\circ}\right]$ & $\Phi\left[^{\circ}\right]$ & $\left.\varphi_{2} l^{\circ}\right]$ & $b\left[^{\circ}\right]$ \\
\hline 1 & 1.8 & 54.8 & 2.4 & 35.8 & 5.6 \\
\hline 2 & 3.5 & 2.0 & 44.6 & 84.0 & 3.6 \\
\hline 3 & 5.5 & 93.9 & 44.9 & 86.3 & 4.9 \\
\hline 4 & 2.5 & 23.8 & 24.8 & 89.5 & 7.2 \\
\hline 5 & 9.6 & 117.5 & 23.2 & 88.2 & 16.0 \\
\hline 6 & 4.8 & 161.2 & 26.7 & 84.2 & 9.5 \\
\hline 7 & 2.3 & 73.9 & 26.1 & 82.6 & 6.8 \\
\hline 8 & 4.3 & 135.7 & 36.0 & 36.8 & 11.5 \\
\hline 9 & 2.1 & 95.1 & 39.6 & 7.7 & 7.0 \\
\hline
\end{tabular}

- Orientation differences between calculated components may give an indication to crystal planes or directions which are invariant during the texture modifying process.

- An uncommon statistical symmetry can be determined with respect to the sample coordinate system. This finding may provide information about the symmetry of the effective process or about correlations between substrate and layer (Helming et al., 1995).

- Any pole figure can be calculated from the component ODF irrespective the fact that it can be measured or not, if the diffraction peaks overlap or the structure factor is too low.

\section{References}

Bunge, H. J. (1965). Zur Darstellung allgemeiner Texturen. Z. Metallkunde 56, 872-874.

Bunge, H. J. (1982). Texture Analysis in Materials Science - Mathematical Methods, Butterworth London.

Bunge, H. J., Dahms, M. and Brokmeier, H. G. (1989). The determination of integrated intensities from polycrystalline samples with preferred orientations, Cryst. Rev. 2, 67-88.

Dahms, M. and Bunge, H. J. (1989). The iterative series expansion method for quantitative texture analysis. I. General Outline, J. Appl. Crystl. 22, 439-447.

Geier, S., Hessmer, R., Preckwinkel, U., Schweitzer, D., Schreck, M. and Rauschenbach B. (1996). Study of the initial growth phase of chemical vapor deposited diamond on silicon (001) by synchrotron radiation. J. Appl. Phys. 79, accepted for publication.

Helming, K. and Eschner, Th. (1990). A new approach to texture analysis of multiphase materials using a texture component model, Cryst. Res. Technol. 25, K203-K208.

Helming, K. (1992). Minimal pole figure ranges for quantitative texture analysis, Textures and Microstructures 19, 45-54.

Helming, K. (1994). Geometric approximation method for texture analysis of rocks, Physics on the Solid Earth, engl. translation: Vol. 29, No. 6, 523-532.

Helming, K. and Schwarzer, R. A. (1994). Texture estimates from minimum ranges of SAD pole figures, Materials Science Forum 157-162, 1219-1224.

Helming, K., Schwarzer, R. A., Rauschenbach, B., Geier, S., Leiss, B., Wenk, H.-R., Ullemeier, K. and Heinitz, J. (1994). Texture estimates by means of components, Z. Metallkunde 85, 545-553. 
Helming, K., Geier, S., Schreck M., Hessmer, R., Rauschenbach, B. and Stritzker B. (1995). Texture analysis of CVD-films on silicon by the component method. J. Appl. Phys. 77, 4765.

Henke, S., Stritzker, B. and Rauschenbach, B. (1995). Synthesis of expitaxial $\beta$-SiC by $C_{60}$-carbonization of silicon. J. Appl. Phys. 78, 2070.

Lücke, K., Pospiech, J., Jura, J. and Hirsch, J. (1986). On the representation of orientation distribution functions by model functions, Z. Metallkunde 77, 312-321.

Matthies, S., Vinel, G. and Helming, K. (1987-1990). Standard distributions in texture analysis. Vol. 1-3, Akademie-Verlag Berlin.

Schwarzer, R. (1983). Intensitätskorrektur für die Messung von Polfiguren im TEM, Beitr. Elektronenmikroskop. Direktabb. Oberfl. (BEDO) 16, 131-134.

Schwarzer, R. (1985). Polfigurmessung mit einem computergesteuerten TransmissionsElektronenmikroskop, Beitr. elektronenmikroskop. Direktabb. Oberfl. (BEDO) 18, 61-68.

Wassermann, G. (1939), Texturen metallischer Werkstoffe, Springer Verlag Berlin. 